\title{
An emerging allergen: Cannabis sativa allergy in a climate of recent legalization
}

\author{
Bradley Jackson ${ }^{1}$ (D) Erica Cleto $^{2}$ and Samira Jeimy ${ }^{3,4^{*}}$
}

\begin{abstract}
Considering its recent legalization in Canada, the health implications of Cannabis sativa exposure, including allergy, are coming to the forefront of medical study and interest. C. sativa allergy is an issue that affects recreational users of the substance, processors, agricultural workers, and contacts of Cannabis aeroallergens and secondhand product. Allergies to C. sativa are heterogenous and span the spectrum of hypersensitivity, from dermatitis to rhinoconjunctivitis to life-threatening anaphylaxis. Due to its recent legalization, sensitized individuals will have increasing exposure from direct contact to agricultural pollens. Diagnosis and treatment of Cannabis allergy are developing fields that are already showing promise in the identification of culprit antigens and the potential for immunotherapy; however, much responsibility still falls on clinical diagnosis and symptom management. Hopefully, given the current explosion of interest in and use of Cannabis, C. sativa allergy will continue to garner awareness and therapeutic strategies.
\end{abstract}

Keywords: Cannabis sativa, Allergy, Marijuana

\section{Background}

Cannabis sativa allergy is a hypersensitivity that has recently been gaining relevance and is of particular interest due to recent legalization in Canada. Approximately $17 \%$ of Canadians, and $27 \%$ of those 25-24 years old, report Cannabis use within the past 3 months [1]. Cannabis sativa allergy is expected to increase as a consequence of legalization due to increased exposure. Additionally, as legal and stigma-related barriers to use subside, an unintentional side effect of legalization may be increased reporting of current suspected cases of Cannabis allergy. Given the potential for increases in existing and reported allergic reactions to Cannabis, building an understanding of C. sativa allergy spectrum, diagnosis, and treatment will be important moving forward.

*Correspondence: jeimysb@gmail.com

${ }^{4}$ B3-112, St. Joseph's Healthcare London, 268 Grosvenor Street, London, ON N6A 4V2, Canada

Full list of author information is available at the end of the article
The purpose of this article is to provide an overview of the current understanding of Cannabis allergy and place it within a Canadian context. This article also highlights that exposure extends beyond recreational use and includes second-hand exposure, ingestion, aeroallergen contact, and cutaneous contact.

\section{Spectrum of C. sativa allergy}

Cannabis is a complex genus of dioecious, annual, windpollinated herbs that diverged from Humulus-a small genus that includes $H$. lupulus, whose bitter female flowers form the hops used to flavor beer-approximately 27.8 million years ago [2]. Cannabis is among humanity's oldest crops with records of its use for food, fiber, medicine, and inebriation dating back over 6000 years. Despite its long history of use, its taxonomy remains disputed, with some suggesting a monotypic classification with several subspecies of $C$. sativa [2], and others suggesting three distinct species $(C$. sativa, $C$. indica, and C. ruderalis) [3, 4]. The biochemistry of Cannabis is similarly complex, with at least 118 cannabinoids and 489 described constituents, the most well know

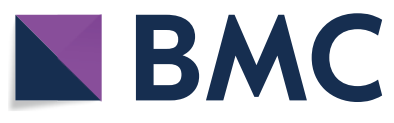

(c) The Author(s) 2020. This article is licensed under a Creative Commons Attribution 4.0 International License, which permits use, sharing, adaptation, distribution and reproduction in any medium or format, as long as you give appropriate credit to the original author(s) and the source, provide a link to the Creative Commons licence, and indicate if changes were made. The images or other third party material in this article are included in the article's Creative Commons licence, unless indicated otherwise in a credit line to the material. If material is not included in the article's Creative Commons licence and your intended use is not permitted by statutory regulation or exceeds the permitted use, you will need to obtain permission directly from the copyright holder. To view a copy of this licence, visit http://creativecommons.org/licenses/by/4.0/. The Creative Commons Public Domain Dedication waiver (http://creativecommons.org/ publicdomain/zero/1.0/) applies to the data made available in this article, unless otherwise stated in a credit line to the data. 
and psychoactive of which being tetrahydrocannabinol (THC) and cannabidiol (CBD) [5]. "Indica" varieties of Cannabis tend to have a higher THC content, and higher THC to CBD ratio than "sativa" varieties [2]. "Indica" varieties are known for a more mellow high and a terpenoid profile with an acrid, skunk smell, whereas "sativa" varieties are known for a more exciting high and a sweet, herbal aroma [2]. However, these strains are heterogeneous with genome-wide variability that is not limited solely to the genes involved in THC and CBD production [4].

Study of specific culprit Cannabis allergens is still in its infancy. A handful of IgE immunoblot experiments, summarized in Table 1, have identified several potential allergens. Of these, the Cannabis non-specific lipid transfer protein (nsLTP), Can s 3, was the first identified and is the best studied [6]. Thaumatin-like protein (TLP), ribulose-1,5-bisphosphate carboxylase oxygenase (RuBisCO), and oxygen evolving enhancer protein 2 have also been recognized as potential sensitizing allergens in Cannabis allergy [7, 8].

Cannabis sensitivity spans the spectrum of allergic response. As an aeroallergen, Cannabis pollen has been implicated in allergic rhinitis, allergic keratoconjunctivitis, hypersensitivity pneumonitis, and exacerbations of asthma symptoms [9] (Fig. 1a). Additionally, patients may experience cutaneous reactions in the form of generalized pruritus, contact urticaria, and angioedema. A case of occupational contact urticaria was reported in a forensic sciences technician who had regular occupational contact with Cannabis for a period of 2 years. She was neither a recreational user, nor an atopic or dermatographic individual, suggesting sensitization specifically from repeated handling [10]. Erythema multiforme (in one case report) has also been associated with recreational consumption [11]. This individual experienced the eruption of vesicobullous, scaled, and targetoid rash on his distal extremities which progressed proximally to his trunk within a two-week period, waxing and waning synchronously with his use of Cannabis [11]. Anaphylaxis to $C$. sativa with hempseed ingestion, smoking, and injection have also been reported [12-14].

Cannabis has reasonably common, expected, but undesirable physiologic effects (conjunctival injection, sinus tachycardia, orthostatic hypotension, anxiety or panic reactions, dysphoria). It is important to not ignore or mis-attribute similar symptoms when the index of suspicion for a serious reaction or anaphylaxis is high [9].

Cannabis consumption also carries a risk to immunosuppressed patients in the form of microbiological contaminants, particularly when inhaled. Aspergillus has been isolated repeatedly from Cannabis samples [15, 16]. In one observational study, a majority of Cannabis users had antibody evidence of Aspergillus exposure compared to a minority of abstinent controls [17]. Furthermore, cases of pulmonary aspergillosis have been linked to contaminated Cannabis use in immunosuppressed populations [16, 17]. Fungal spores resist destruction from smoking and vaporization [18]. Thus, hypersensitivity and immunosuppression are clinically relevant states with regard to Cannabis consumption.

Table 1 Summary of possible Cannabis allergens

\begin{tabular}{|c|c|c|c|c|}
\hline Molecular weight & Genbank nucleotide & Genbank protein & Description & Study \\
\hline $9 \mathrm{kDa}$ & HE972341.1 & CCK33472.1 & Lipid transfer protein precursor, partial (chloroplast) & Gamboa et al. [6] \\
\hline 10 kDa & HE972341.1 & P86838.1 & Non-specific lipid-transfer protein & Larramendi et al. [7] \\
\hline 38 kDa & XM_030636673.1 & XP_030492533.1 & Thaumatin-like protein 1b & \\
\hline 53 kDa & JP454288.1 & YP_009123081.1 & $\begin{array}{l}\text { Ribulose 1,5-bisphosphate carboxylase/oxygenase large subunit } \\
\text { (chloroplast) }\end{array}$ & Nayak et al. [8] \\
\hline 54 kDa & JP462165.1 & YP_009123080.1 & ATP synthase CF1 beta subunit (chloroplast) & \\
\hline 29 kDa & JP475070.1 & XP_030482568.1 & Oxygen-evolving enhancer protein 2, chloroplastic & \\
\hline $49 \mathrm{kDa}$ & JP458088.1 & XP_030492156.1 & $\begin{array}{l}\text { Ribulose bisphosphate carboxylase/oxygenase activase, } \\
\text { chloroplastic isoform X2 }\end{array}$ & \\
\hline 52 kDa & JP451043.1 & XP_030504809.1 & $\begin{array}{l}\text { Ribulose bisphosphate carboxylase/oxygenase activase } 2 \text {, } \\
\text { chloroplastic-like }\end{array}$ & \\
\hline 48 kDa & JP450816.1 & XP_030507192.1 & Glutamine synthetase leaf isozyme, chloroplastic & \\
\hline $51 \mathrm{kDa}$ & JP458176.1 & PON58274.1 & Phosphoglycerate kinase (Trema orientale) & \\
\hline $47 \mathrm{kDa}$ & JP473302.1 & XP_030489218.1 & Fluoride export protein 2-like isoform X1 & \\
\hline 48 kDa & JP452228.1 & PON90495.1 & $\begin{array}{l}\text { Glyceraldehyde-3-phosphate dehydrogenase, type I (Trema } \\
\text { orientale) }\end{array}$ & \\
\hline
\end{tabular}




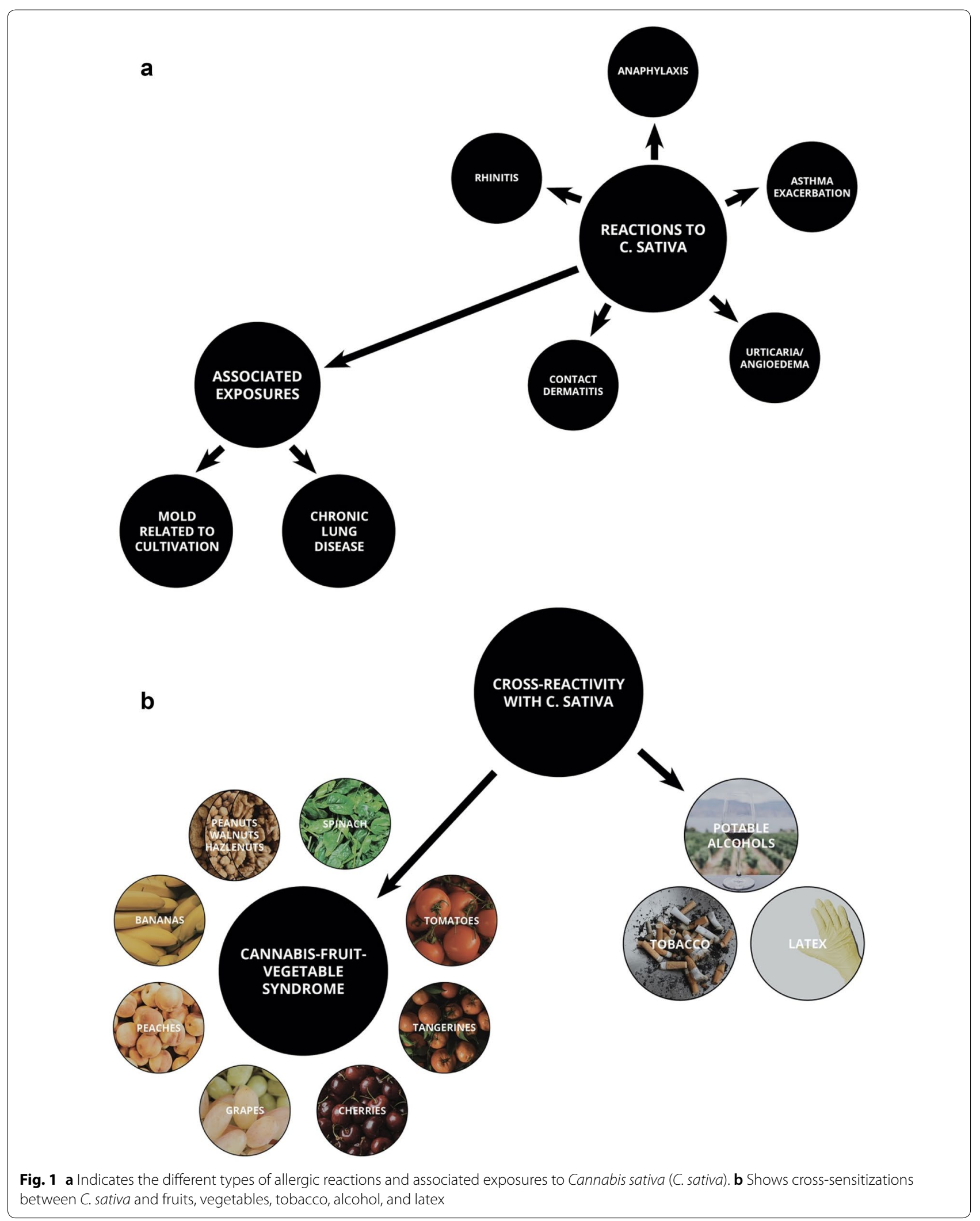




\section{Sensitization to C. Sativa}

Sensitization to Cannabis can occur via inhalation, cutaneous exposure, ingestion, and secondhand exposure, and can occur in recreational users and occupational handlers. Specifically, sensitization and reactions have been seen with smoking, consuming, injecting, and handling Cannabis plants, the latter being most germane to industrial workers [19-21]. As the Cannabis agricultural industry grows, $C$. sativa may also become a significant aeroallergen. Indeed, Canada's first large-scale commercial outdoor Cannabis farm began operations in mid-summer 2019 [22]. The potential role of Cannabis pollen as an aeroallergen has long been realized in agricultural regions. For example, in Nebraska, peak season pollen counts show Cannabis comprising $36 \%$ of the total airborne burden, and additionally correlating with a skin-test positive allergic symptom surge during mid to late August [23].

In light of this increase in Cannabis aeroallergen, we may also begin to see an increase in Cannabisfruit/vegetable syndrome. As with other forms of food-pollen or oral allergy syndrome, Cannabis-fruit/ vegetable syndrome is thought to occur due to structural homology and antigenic similarities between nsLTPs in C. sativa and those in cherry, tangerine, peach, tomato, hazelnut, latex, and tobacco (Fig. 1b), resulting in cross-sensitivity and reaction to consumption of these products $[7,9,19]$. However, unlike birch pollenrelated food-pollen syndrome, Cannabis-fruit/vegetable syndrome may cause more severe symptoms (including anaphylaxis to previously tolerated fruit). Sensitization is bidirectional; i.e. sensitization to an nsLTP in fruits can cause subsequent sensitization to Cannabis [7, 19, 20]. Thus, a variety of exposure routes exist for C. sativa sensitization, and these sensitizations may be primary or cross-reactive.

\section{Diagnosis of C. sativa allergy: an evolving practice}

Clinical history is the cornerstone of diagnosing Cannabis hypersensitivity. As with any other allergic presentation, a complete history will include a detailed review of the presenting suspected reaction (Table 2). The history should also include a thorough review of atopic history, medical history, medications, social history including recreational and occupational exposures, and family history including atopy and asthma. With respect to diagnostic testing, the "gold standard" allergen challenge may not be appropriate in Cannabis allergy. Although Canadian law would permit access to and use of the substance unlike many regions, there is dispute regarding expected reaction phenotypes, particularly regarding varied and paradoxical lower airway response [20]. Thus, Cannabis graded challenge is
Table 2 Suggested prompts for a history of presenting suspected reaction to a $C$. sativa product

Suggestions for characterizing the history of a possible presenting reaction to C. sativa

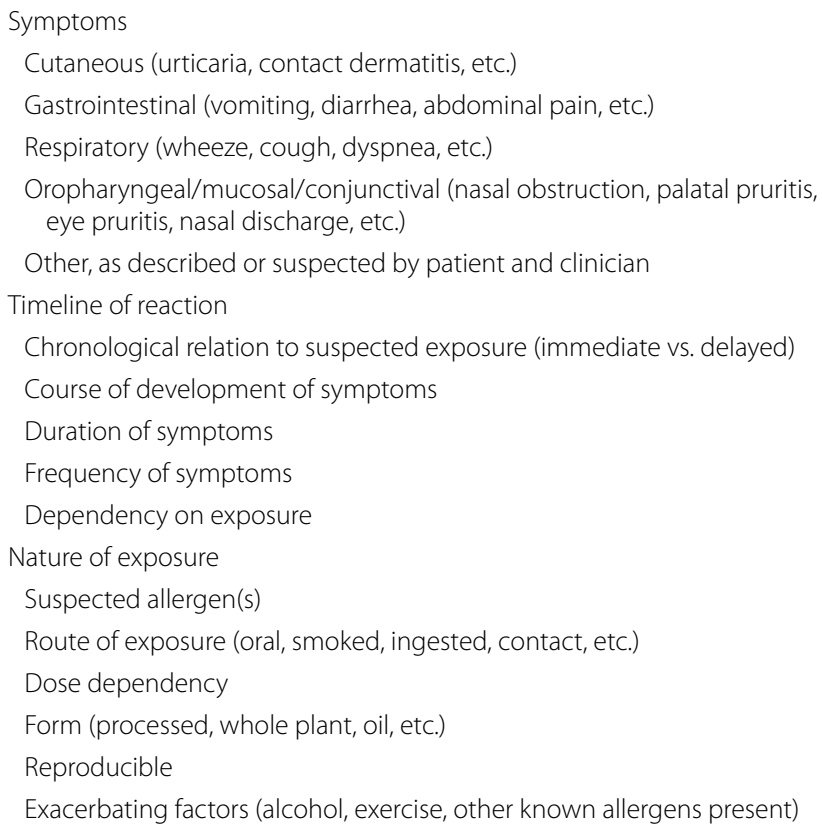

Adapted from consultation template prompts from the Division of Clinical Immunology and Allergy at St. Joseph's Healthcare in London, ON

not yet a viable, routine diagnostic option. Epicutaneous testing is currently not standardized for C. sativa. Skin testing described in current literature is heterogenous and requires the suspension of marijuana buds, leaves, and/or flowers to be produced and administered by the allergist [20]. In vitro assays of serum specific IgE (sIgE), cytometric basophil activation (BAT), and basophil histamine release using crude extracts, purified components and recombinantly expressed allergens have shown promising results, but remain commercially unavailable [20, 21, 24, 25].

The isolation of specific Cannabis antigens will facilitate standardized skin prick and serum IgE testing. Recently, Decuyper et al compared specific IgE (sIgE) testing to hemp, sIgE to a recombinant Can s 3 (rCan s 3) protein, BAT to the same rCan s 3, and skin prick testing with a Can s 3 antigen-rich extract in diagnosing Cannabis allergy [20]. The Can s 3 extract, which is not commercially available, was prepared for study using methods previously described for isolating nsLTPs from tomato, with total protein quantification using Micro BCA Protein Assay [20, 24, 26]. The results of the comparison suggested that Can s 3 is the superior antigen for testing, and that skin prick and sIgE testing are effective and practical, with respective sensitivities 
of $72 \%$ and $81 \%$ and specificities of $63 \%$ and $87 \%$ [20]. While promising, the authors address the clear issue of lack of commercial availability of these extracts. They suggest that, with current clinical limitations, a sIgE to hemp (which is currently available from Thermo Fisher) may be appropriate for diagnosis as only $18 \%$ of Cannabis sensitized individuals have negative IgE to hemp. However, it would still be ideal that a commercially available Can s 3 extract become available.

\section{Treatment of C. sativa allergy}

The only proven, currently available treatment for Cannabis allergy is avoidance. However, when avoidance is impossible, treatment of C. sativa allergy is identical to that of other allergens: based on the index reaction to the substance. Treatment with antihistamines, intranasal corticosteroid sprays, and ophthalmic antihistamine drops can provide symptom relief [9]. All individuals with anaphylactic allergies should carry auto-injectable epinephrine. Treatment for Cannabis-fruit-vegetable syndrome is also dependent on avoidance.

Promising but limited case reports suggest future directions for the treatment of Cannabis allergy. For example, Engler et al. described an occupationally exposed individual with anaphylaxis to Cannabis who was successfully treated for with Omalizumab therapy [27]. Kumar et al. successfully implemented a perennial subcutaneous immunotherapy schedule that reduced a patient's symptoms of allergic rhinitis and asthma during Cannabis pollen season [28]. This was delivered as subcutaneous, twice-weekly doses starting with 1:5000 weight/volume of diluted antigen, beginning at $0.1 \mathrm{~mL}$ and increasing by $0.1 \mathrm{~mL}$ per injection to a target maintenance dose of $1 \mathrm{~mL}$ of 1: 50 antigen concentration per month for 1 year [28].

Hopefully, in light of the rise of C. sativa use and agriculture, desensitization protocols will become available for sensitive patients as demand increases. Nonetheless, avoidance and traditional methods of managing allergic reactions continue to be the basis of treatment for Cannabis allergy.

\section{Conclusion}

The legalization and accessibility of Cannabis sativa in Canada has created a renewed interest in the health implications of its use, including allergic and immunologic consequences. This brief review has highlighted the diversity of sensitization routes and reactions to the plant, emphasizing the heterogenous presentation of Cannabis allergy. In addition, this article has underscored the fledgling nature of available testing and treatment options for C. sativa allergy. There have been recent, exciting advancements in isolation of culprit allergens and clinical testing, although these are not yet applicable to general office use. At the moment, there are existing practical suggestions for diagnosing and treating $C$. sativa allergy, which will hopefully evolve in the coming years as Can $\mathrm{s} 3$ preparations and immunotherapy schedules mature and become commercially available. However, currently, a detailed allergy history with adjunct hemp sIgE testing are the cornerstones of diagnosis, and avoidance (in combination with standard symptomatic treatment) is the mainstay of treatment.

\section{Abbreviations \\ C. sativa: Cannabis sativa; LTP: Lipid transfer protein; Ns: Non-specific; TLP: Thaumatin-like protein; slgE: Serum immunoglobulin E; BAT: Basophil activation testing. \\ Acknowledgements \\ None. \\ Authors' contributions \\ BJ, EC and SJ contributed equally to the writing of this paper. SJ Initiated and coordinated the conception of the paper. BJ, EC and SJ gathered data and developed the manuscript. All authors read and approved the final manuscript \\ Funding \\ Not applicable.}

Availability of data and materials

Not applicable.

Ethics approval and consent to participate

Not applicable.

Consent for publication

Not applicable.

\section{Competing interests}

The authors declare that they have no competing interests.

\section{Author details}

${ }^{1}$ Department of Paediatrics, Children's Hospital, London Health Sciences Centre, London, ON, Canada. ${ }^{2}$ Schulich School of Medicine and Dentistry, Western University, London, ON, Canada. ${ }^{3}$ Division of Clinical Immunology and Allergy, Department of Medicine, Western University, London, ON, Canada. ${ }^{4}$ B3-112, St. Joseph's Healthcare London, 268 Grosvenor Street, London, ON N6A 4V2, Canada.

Received: 20 June 2019 Accepted: 4 June 2020

Published online: 26 June 2020

\section{References}

1. Cannabis Stats Hub. https://www150.statcan.gc.ca/n1/pub/13-610-x/ cannabis-eng.htm. Accessed 24 Feb 2020.

2. McPartland JM. Cannabis systematics at the levels of family, genus, and species. Cannabis Cannabinoid Res. 2018;3:203-12.

3. Hillig KW. Genetic evidence for speciation in Cannabis (Cannabaceae) Genet Resour Crop Evol. 2005;52:161-80.

4. Sawler J, Stout JM, Gardner KM, Hudson D, Vidmar J, Butler L, et al. The genetic structure of marijuana and hemp. PLoS ONE. 2015;10:e0133292.

5. ElSohly MA, Slade D. Chemical constituents of marijuana: the complex mixture of natural cannabinoids. Life Sci. 2005:78:539-48. 
6. Gamboa P, Sanchez-Monge R, Sanz ML, Palacín A, Salcedo G, Diaz-Perales A. Sensitization to Cannabis sativa caused by a novel allergenic lipid transfer protein, Can s 3. J Allergy Clin Immunol. 2007;120:1459-60.

7. Larramendi CH, López-Matas MÁ, Ferrer Á, Huertas ÁJ, Pagán JA, Navarro $L A$, et al. Prevalence of sensitization to Cannabis sativa lipid-transfer and thaumatin-like proteins are relevant allergens. Int Arch Allergy Immunol. 2013;162:115-22.

8. Nayak AP, Green BJ, Sussman G, Berlin N, Lata H, Chandra S, et al. Characterization of Cannabis sativa allergens. Ann Allergy Asthma Immunol. 2013;111(32-37):e4.

9. Ocampo TL, Rans TS. Cannabis sativa: the unconventional 'weed' allergen. Ann Allergy Asthma Immunol. 2015;114:187-92.

10. Williams C, Thompstone J, Wilkinson M. Work-related contact urticaria to Cannabis sativa. Contact Dermatitis. 2008:58:62-3.

11. Ozyurt S, Muderrisoglu F, Ermete M, Afsar F. Cannabis-induced erythema multiforme-like recurrent drug eruption. Int J Dermatol. 2014;53:e22-3.

12. Liskow B, Liss JL, Parker CW. Allergy to marihuana. Ann Intern Med. 1971;75:571-3.

13. Gilbert JD, Grabowski M, Byard RW. Intravenous administration of cannabis and lethal anaphylaxis. Med Sci Law. 2017;57:91-4.

14. Stadtmauer G, Beyer K, Bardina L, Sicherer SH. Anaphylaxis to ingestion of hempseed (Cannabis sativa) [7]. J Allergy Clin Immunol. 2003;112:216-7.

15. Thompson GR, Tuscano JM, Dennis M, Singapuri A, Libertini S, Gaudino $R$, et al. A microbiome assessment of medical marijuana. Clin Microbiol Infect. 2017;23:269-70.

16. Szyper-Kravitz M, Lang R, Manor Y, Lahav M. Early invasive pulmonary aspergillosis in a leukemia patient linked to aspergillus contaminated marijuana smoking. Leuk Lymphoma. 2001;42:1433-7.

17. McLaren J, Swift W, Dillon P, Allsop S. Cannabis potency and contamination: a review of the literature. Addiction. 2008;103:1 100-9.

18. Moody MM, Wharton RC, Schnaper N, Schimpff SC. Do water pipes prevent transmission of fungi from contaminated marijuana? N Engl J Med. 1982;306:1492-3.

19. Decuyper II, Van Gasse AL, Cop N, Sabato V, Faber MA, Mertens C, et al. Cannabis sativa allergy: looking through the fog. Allergy Eur J Allergy Clin Immunol. 2017;72:201-6.
20. Decuyper II, Van Gasse AL, Faber MA, Elst J, Mertens C, Rihs H-P, et al. Exploring the diagnosis and profile of cannabis allergy. J Allergy Clin Immunol Pract. 2019;7(983-989):e5.

21. Herzinger T, Schöpf P, Przybilla B, Ruëff F. IgE-mediated hypersensitivity reactions to cannabis in laboratory personnel. Int Arch Allergy Immunol. 2011;156:423-6.

22. Preparations underway at Canada's soon-to-be largest outdoor cannabis farm | CTV News. https://www.ctvnews.ca/canada/canada-s-large st-outdoor-cannabis-farm-ready-for-growth-1.4441978. Accessed 24 Feb 2020.

23. Stokes JR, Hartel R, Ford LB, Casale TB. Cannabis (hemp) positive skin tests and respiratory symptoms. Ann Allergy Asthma Immunol. 2000:85:238-40.

24. Ebo DG, Swerts S, Sabato V, Hagendorens MM, Bridts CH, Jorens PG, et al, New food allergies in a european non-mediterranean region: Is cannabis sativa to blame? Int Arch Allergy Immunol. 2013;161:220-8.

25. Decuyper II, Faber MA, Lapeere H, Mertens C, Rihs HP, Van Gasse AL, et al. Cannabis allergy: a diagnostic challenge. Allergy Eur J Allergy Clin Immunol. 2018;73:1911-4.

26. Tomassen MMM, Barrett DM, van der Valk HCPM, Woltering EJ. Isolation and characterization of a tomato non-specific lipid transfer protein involved in polygalacturonase-mediated pectin degradation. J Exp Bot. 2007;58:1151-60.

27. Engler DB, Malick AA, Saraf SK, Dargel LA. Severe marijuana allergy controlled with omalizumab. J Allergy Clin Immunol. 2013;131:215.

28. Kumar R, Gupta N. A case of bronchial asthma and allergic rhinitis exacerbated during Cannabis pollination and subsequently controlled by subcutaneous immunotherapy. Indian J Allergy Asthma Immunol. 2013;27:143.

\section{Publisher's Note}

Springer Nature remains neutral with regard to jurisdictional claims in published maps and institutional affiliations.
Ready to submit your research? Choose BMC and benefit from:

- fast, convenient online submission

- thorough peer review by experienced researchers in your field

- rapid publication on acceptance

- support for research data, including large and complex data types

- gold Open Access which fosters wider collaboration and increased citations

- maximum visibility for your research: over $100 \mathrm{M}$ website views per year

At BMC, research is always in progress.

Learn more biomedcentral.com/submissions 